\title{
The Use-it-Wisely (UIW) Approach
}

\author{
Göran Granholm and Stefan N. Grösser
}

\begin{abstract}
Industrial products and services must be continually upgraded to meet changing demands of enhanced functionality and performance. The digital transformation of industry, together with new emerging technologies, enables improved solutions but at the same time cause increasing complexity and interdependence between system components. New forms of collaboration across the value chain are necessary to deliver sustainable solutions to satisfy current and future needs. The UIW-approach builds on the idea of a continuous incremental upgrade process carried out in collaborative effort between actors and stakeholders with the common objective to achieve a sustainable project life-cycle. Based on this approach a conceptual framework is defined. The UIW-framework includes an adaptation mechanism designed to account for the diverse influence factors affecting the upgrade design, a multi-disciplinary system model definition integrating actor, product and service data, and a virtual collaboration environment to facilitate the interaction between actors and a collection of tools and methods to support the collective efforts. The UIW-framework is used as a template for system implementations in installations in various actor networks.
\end{abstract}

Keywords Industrial product-service system - Collaborative innovation • Innovation network - Circular economy - System upgrade - Business model • Systems engineering

G. Granholm (ه)

VTT Technical Research Centre of Finland Ltd., Espoo, Finland

e-mail: goran.granholm@vtt.fi

S.N. Grösser

Institute for Corporate Development, Bern University of Applied Sciences, Bern, Switzerland

e-mail: stefan.groesser@bfh.ch 


\section{Introduction}

The speed of technological development in concurrence with global economic development and short-term market volatility force companies to find new strategies to compete in the marketplace. The competitiveness of manufacturing firms will be increasingly linked to their ability to rapidly transfer developments in science and technology into their processes and products as well as adopting ideas developed both internally and externally (UNIDO 2013). Foresights of future markets and operating environments (Müller and Müller-Stewens 2009) become crucial when making decisions about investments in innovation and R\&D of products and services that need to create value in the long-term.

The digital transformation of industry is profoundly changing the manufacturing of products, provision of services and structures of value creation in general and of individual businesses in particular. Advances in wireless communication combined with embedded sensor and computation technologies have changed the way humans and machines interact, shaping the concept of cyber-physical systems (Rajkumar et al. 2010). At the same time increased awareness of the effects of human activity on the environment has become an important factor affecting the design of new products as well as upgrade solutions. New business models based on the circular economy vision are being adopted in order to minimise waste and save resources through efficient reuse of material (Parker et al. 2015). A common denominator of much of the current development is the need for closer ties between the involved actors. This is driven both by the growing demand for customised products and services, and the increasing complexity of technical systems requiring cooperation between large numbers of experts and sub-contractors. To stay ahead in the competition, companies increasingly turn to innovation-led strategies and focus on improving R\&D efficiency and value (OECD 2015). In a complex and highly interdependent business environment innovation involves a wide range of actors, including firms, entrepreneurs, foundations and non-profit organisations, universities, scientific institutes, public sector agencies, citizens, and consumers, often working in close collaboration. Managing this collaboration becomes an important target (see also Hurni and Groesser, Chapter "Innovation Management with an Emphasis on Co-creation" in this book).

\subsection{System Obsolescence and Decay of Use Value Require Change}

Systems are designed based on available knowledge to fulfil current and future needs. The objective is to produce value during the system life-cycle to cover investment costs and profit expectations. To sustain their value when markets and user needs change, products and services need to be continually maintained, upgraded and improved. High-investment assets with long payback periods, 
e.g., a production system for a car manufacturer, can provide specific challenges as complete replacements are infrequent and the value of using the system (use value) might become significantly reduced. The capability of suppliers to retain or increase the use value of the asset throughout its planned service life becomes an important, perhaps even decisive, factor for customers' investments decisions.

All technical systems will face a gradual decay of their use value over time. This value degradation is due to both internal factors, such as wear and tear leading to increasing maintenance costs and interrupted operation, and external factors, such as changing market demands, new technologies, and alternative solutions. A further external factor is component obsolescence, i.e., the redesign required as replacement components become obsolete. To account for such obsolescence, systems undergo major upgrades (Engel and Browning 2006).

Technical solutions are often designed to meet current requirements without emphasizing enough that systems inevitably evolve with time (Schulz and Fricke 1999). Moreover, factors that are difficult to measure or deal with are often neglected due to time or cost pressures. Fink et al. (2004) have identified three main traps to avoid when planning for the future: (1) suppression of uncertainty, (2) suppression of complexity, and (3) suppression of change. Avoiding dealing with difficult issues may speed up decision making, but does not eliminate risk, and shifts more difficult decisions to a later point in time. Thus, delaying decisions makes it impossible to manage risks in a systematic and effective way.

Investment decisions have to be made based on information about the future that is inherently uncertain. Managing risk and uncertainty associated with design solutions requires considerable effort. Systems thinking and tools for modelling complexity and causal dependencies (e.g. Anderson and Johnson 1997) may be used to help strategic planning and management by building a common understanding of the implications on the design task and possible future developments (see also Groesser, Chapter "Complexity Management and System Dynamics Thinking" in this book).

\subsection{Adapting to Change in Markets and Environment}

Companies need well-defined strategies to ensure effective adaptation to change. According to Schulz et al. (2000), the major drivers of future development are marketplace dynamics, technological evolution, and variety of environments. Marketplace dynamics can be observed as new markets emerge and existing ones change or converge with others. On the supplier side, new actors appear introducing new offerings, often by employing new, most often digital, business models. On the customer side demands for individualised solutions call for a higher degree of responsiveness and customer adaptation, which in turn require increased agility of design and production processes. Fast technological evolution brings up new opportunities, but also introduces challenges when system life-cycles are longer than the life-cycles of technologies that the systems are built on. This is especially 
the case for industrial product-service systems (IPSS) (cf. the definition in Chapter "Dynamics of Long-Life Assets: The Editors' Intro" of this book), and leads to increasing maintenance costs and expensive upgrades replacing old technologies with new ones. Variety of environments refers to the increasing variety and complexity of technical systems where individual components must be able to adapt to operate as part of different system compositions, i.e., systems of systems (Schulz et al. 2000).

Changes to end products frequently also require changes to the production lines and manufacturing systems, while service changes may require adopting new business models. Thus, changeability requirements may have to target simultaneously the product or service, the way it is manufactured, and the complete value network delivering the value added. Sharing of tasks and resources across various forms of collaboration networks can provide improved capacity to change due to smaller, more agile operators and flexibility of the collaboration network itself. Efficient operation of the supplier network requires a flexible information architecture that supports decentralized collaborative processes (Gunasekaran et al. 2008).

In order to meet future change demands, changeability features must be premeditated and built into the IPSS. Different technological approaches have been developed for this purpose. A quantitative method to model adaptability cost and value fluctuations of given system architectures has been proposed by Engel and Browning (2006).

In parallel with system properties that allow for future change, a streamlined process to support effective adaptation is required to achieve agile adaptation. Companies are increasingly moving from linear product life-cycle process with decoupled supplier and customer views (Fig. 1) to an integrated product-service life-cycle based on a continuous collaboration between actors (Fig. 2).

In the linear product-based process ownership is handed over in a delivery-acquisition transaction, which causes a disruption in the flow of product life-cycle data. This can be due to incompatibility between product data management systems or practices, or because of unwillingness to share data between customer and supplier organisation. In addition, direct personal communication and

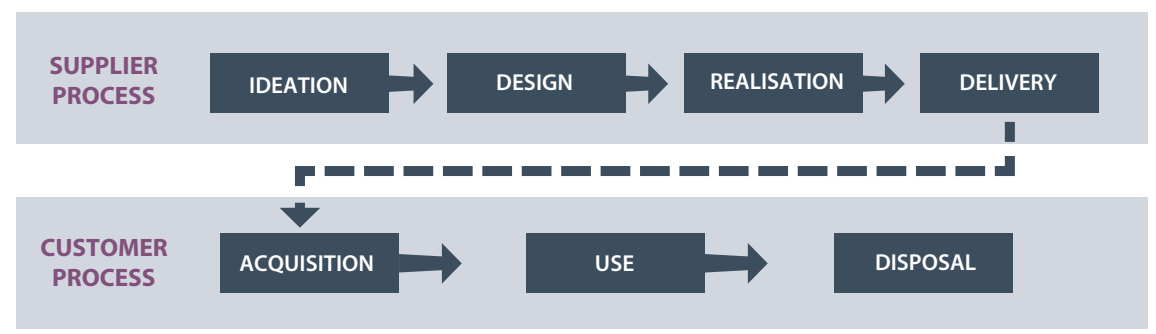

Fig. 1 Linear product life-cycle process with decoupled supplier and customer views 


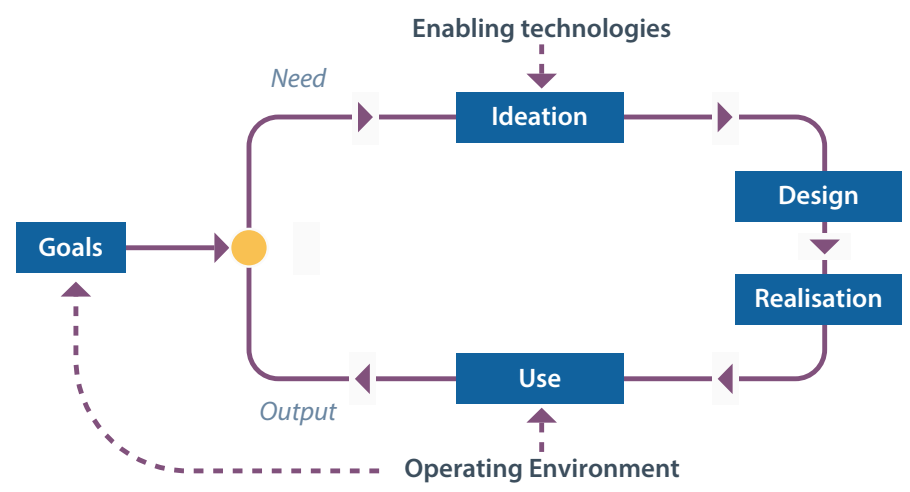

Fig. 2 Integrated customer-supplier product-service life-cycle process

exchange of tacit product knowledge between individuals across company borders is reduced in a life-cycle product model.

Figure 2 shows an integrated collaborative product-service life-cycle process. The main aim of the supplier is not to maximise profit in a single product delivery but to deliver end-user value, for instance as guaranteed up-time or system output. This requires business models focused on the sharing of revenues between the actors contributing to generating the output. As such models are typically based on service provision instead of transfer of ownership, delivery and acquisition sub-processes have been removed. Focusing on end-user value instead of product value creates a shared interest among the actors to maximise the output and to reduce life-cycle costs. This motivates systematic maintenance and continuous adaptation to change: alterations in the operating environment, such as increased production cost, changed market demand and new competition, force the user to set new business goals. The gap between current output and the new goals creates a need to modify the system.

The integrated collaborative product-service life-cycle process model builds on sharing of data across the actor network. Ideally all life-cycle data is accumulated in a shared database. The information on change in system status as well as changes in operating environment or user needs are available as input for successive system updates. This requires closer ties between customer and supplier, and provides a basis for defining structures for networked collaboration for continuous adaptation of industrial product-service systems.

\subsection{The Use-it-Wisely Project}

The Use-it-Wisely (UIW) research project focuses on continuous upgrade of high-investment industrial product-services (IPSS). The goal of the project was to develop an approach to support systematic adaptation to changing needs by 
developing business models and technologies to support collaborative efforts to sustain and improve high-investment IPSS. This chapter describes the research methodology used and the fundamental principles of the approach.

\subsection{Structure of the Chapter}

The chapter is divided into four parts: the introduction in Sect. 1 describes the background including the need and main drivers behind the Use-It-Wisely project idea. Section 2 describes the research methodology applied in the project. Section 3 discusses the main principles of the approach. Section 4 presents an outline of the solution nurtured with brief introductions to six pilot cases.

\section{Research Methodology}

The research was based on a continuous dialog between theory and practice. Theoretical knowledge and science-based methodologies were applied to analyse actual pilot cases. The project took place from September 2013 until November 2016. Feedback and results from practical implementation and testing was recorded and analysed. Six different industries were included in the research, each with a different upgrade case. The gradual progress of the pilot cases was presented and discussed in ten meetings and several workshops within the project. Sharing information and experience between seemingly unrelated pilot cases from different industries served to identify similarities especially in the problem space. The research setting was based on the assumption that creativity is fostered by exposure to groups of people with apparently unrelated tasks and knowledge. This assumption is supported by numerous studies showing that people connected across groups are more familiar with alternative ways of thinking and new ideas emerge from selection and synthesis across the structural holes between groups (Burt 2011). The following outlines the research setting and the research process applied in the UIW-project.

\subsection{Research Setting}

The focus of research was the transition from a linear product-service delivery process to an integrated, continuous process of small-step incremental upgrade innovations based on close collaboration within value chains. The research hinges on two basic assumptions: small upgrade increments and actor collaboration. The reasoning for both is presented in Table 1 . 
Table 1 Rationale behind the main research assumptions

\begin{tabular}{|c|c|}
\hline Assumption & Rationale \\
\hline $\begin{array}{l}\text { Small upgrade } \\
\text { increments }\end{array}$ & $\begin{array}{l}\text { Reduced financial risk due to smaller investment } \\
\text { Reduced technical risk due to smaller changes } \\
\text { Shorter disruptions } \\
\text { Shorter implementation time leading to faster response times and } \\
\text { enhanced upgrade agility } \\
\text { Reduced environmental impact due to extended use of major system parts }\end{array}$ \\
\hline Actor collaboration & $\begin{array}{l}\text { Important system knowledge exists outside of the corporate borders, on } \\
\text { multiple levels } \\
\text { System defect, deficiencies and changing user needs are communicated } \\
\text { directly and proactively across the network } \\
\text { Sustained actor involvement leads to deeper engagement and firm actor } \\
\text { networks, building trust and loyalty between partners }\end{array}$ \\
\hline
\end{tabular}

Table 2 Industrial clusters included in the study and their primary research target

\begin{tabular}{l|l|l}
\hline Cluster & Industry sector & Primary research target \\
\hline 1 & Energy production & Turbine service inspection \\
\hline 2 & Heavy machinery & Upgrade service for mobile rock crushers \\
\hline 3 & Aerospace & Integrated system data management \\
\hline 5 & Automotive & Production line configuration \\
\hline 6 & Shipbuilding & Value chain collaboration \\
\hline
\end{tabular}

To ensure a wide applicability of the results, companies from six different industries were included in the study: energy production, heavy machinery, aerospace, automotive, shipbuilding and furniture. For each of the six industries, a cluster was formed, consisting of two to four organisations representing parts of the value network. One organisation responsible for technical and scientific research was included in each cluster. The clusters defined their own use cases based on identified needs or foreseen business potential. The use cases included specific research targets including maintenance inspection, upgrade service development, model-based systems engineering, and circular economy. Table 2 presents the industry sector and primary research target of the six clusters. The cluster cases are presented in more detail in Section III of this book.

We included these industries not because of their differences, but because of their commonality. Common between the six industry clusters and their use cases was the focus on IPSS. Another commonality was that the product-services could be classified as "high-investment", at least in relation to the size of client businesses, or to the expected rate of return on investment in the system. This definition of high-investment product-services implies relatively long life-cycles, due to long repayment periods and relatively small financial assets available for complete system recommissioning. In some cases, the push towards long life-cycle solutions was due to potential risks and complications associated with complete system replacement, such as incompatibility with connected legacy systems or 
unacceptably long service disruptions. The need to further extending life-cycles could also be caused by environmental motives, driven by user requirements or societal push. Inherently long system life-cycles and the push for further life cycle extension motivate the need for repeated system upgrades.

Within each cluster the viewpoints of a broad range of actors, such as design engineers, service personnel, sales staff, managers, decision makers, and end users, were taken into account to create comprehensive systems views. The broad scope of the study allowed for applications supporting both a horizontal integration, i.e., through the life-cycle, and vertical integration, i.e., "shop-floor to top-floor". In addition, the collaboration between research and practice as well as between seemingly unrelated industries proved beneficial and provided new viewpoints to identified problems (Fox and Groesser 2016). This observation is in line with previous research supporting the hypothesis that good ideas emerges from the intersection of diverse social worlds, i.e., across "structural holes" in knowledge networks (Burt 2011).

The research setting, including the six industry clusters, different research targets and multiple actor viewpoints, provided the material to study applications on two different levels: first, on a generic level to analyse commonalities across the clusters and conceptually develop the UIW-approach for dealing with shared issues. And second, on a cluster-specific level to analyse individual use cases to provide bespoke solutions based on the tools and methods of the UIW-framework. This two-level approach was designed to ensure the applicability and practice-orientation of the UIW-approach and the transferability of specific solutions to other industries facing similar challenges.

\subsection{Research Process}

The research followed an iterative approach. The cluster cases were analysed to identify specific challenges and business opportunities and to extract commonalities. The goal was to apply a holistic approach to discover latent mechanisms and causal dependencies that could affect the outcome of introduced change, and eventually the success of suggested upgrades. Rich pictures were used to facilitate communication between actors on different levels and to create a shared view of the target case. Business perspectives were analysed using causal context models and system dynamics (SD) modelling to be able to identify influence factors and causal relationships (see Groesser, Chapter "Complexity Management and System Dynamics Thinking" in this book).

In successive iterations analysis was refined and tools for further enhancing collaboration and data management were developed. Virtual and augmented reality techniques were selected to develop collaboration applications facilitating communication between various actors. To deal with upcoming research or development issues of interest across clusters, dedicated task forces were set up as needed. 
The topics of these task forces ranged from overall system architecture and implementation mock-ups to data modelling, simulation and use of individual software tools. The task force concept provided improved agility to work in a result-oriented way on defined topics on their own schedule. The iterative approach applied in the project enabled a continuous interplay between conceptual and empirical methods. It also facilitated a continuous collaboration between researchers and practitioners in different stages of development.

The results of the iterative development process were collected and reported by each of the clusters. The generic tools and methods used for the analysis of the use cases and the experience from applying specific technologies in the implementation of technical solutions targeting concrete development needs were collected to form the foundation of the UIW-approach to support innovative upgrades of high-investment product-services. The final stage included a sequence of on-site demonstrations of the pilot cases. The final UIW-approach is described in detail in Sect. 4.

Figure 3 shows the research process covering areas of theory and research, cross-domain collaboration and knowledge creation, and application in specific industry networks.

The research covered three main areas of activities: research (A), collaboration (B), and application (C). Research activities targeting the general approach (A.1) deal with the basic, theoretical foundation of UIW and strived to ensure that methodologies applied in various activities are founded on scientific evidence. They also aimed to facilitate the transfer of new knowledge to practice. The principles of the general approach are presented in Sect. 3. Based on relevant general research topics, a number of focus areas were selected (A.2) to support the development of shared knowledge, tools and methods (B.2) and to populate the Use-it-Wisely "tool box". Current focus areas and corresponding tools are described in Section II of this book. A community of practise (B.1) consisting of project partners was engaged with collaboration across industry and between research and practice. The community maintained collaboration across selected focus areas and contributed to developing shared knowledge and tools (B.2). With the help of the community of

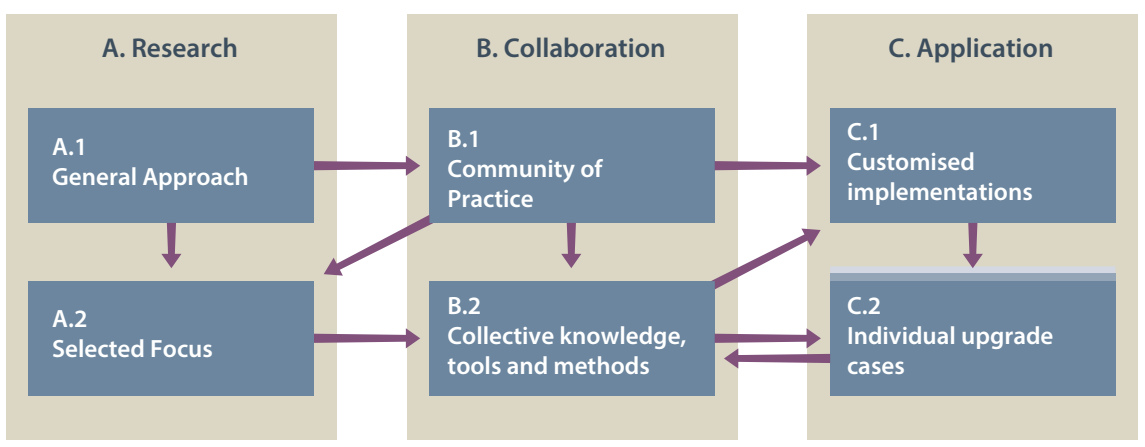

Fig. 3 Research process for the UIW-project 
practice and the generic tools and methods were customised and implemented to meet the needs of specific actor networks (C.1). The adapted tool-box was then used in individual upgrade development cases (C.2).

\section{Principles of the UIW-Approach}

In the following, we introduce six principles which provide a foundation for the UIW-approach.

\subsection{A Holistic System View}

Transitioning from a product-based economy to models based on provision user value or output requires new forms of collaboration. Instead of focusing on revenues from individual sales transactions along the value chain service-based models must find ways to maximise total end-user value. This requires a thorough understanding of the business drivers and implications of both the end user and of the contributors in the value network. It also requires an understanding of the technical components of the system and of new emerging technologies that may impact future system implementations, markets and competitors. Making the right decisions with regard to system design, upgrade interventions and business model development must be based on a holistic systems view. Creating and evolving a comprehensive, shared view requires the combined efforts of the involved actors. Various tools can be used to model causes and effects of alternative decisions. These are described in more detail in Chapter "Complexity Management and System Dynamics Thinking" of this book.

\subsection{Continual Improvement}

The principle of continuous improvement has gained much attention since Imai introduced the approach called Kaizen (Imai 1986). This approach focuses on efficiency based in the identification, reduction and elimination of sub-optimal processes based on continuous and immediate feedback. However, continual improvement of all aspects of a firm's activities is necessary for meeting the challenges of evolving environments and changing customer needs (Bessant and Caffyn 1997). This includes the capability to continually renew and improve product and service offerings. To enable continuous improvement organisations need to manage their innovation process effectively and make sure that it is fed with a constant steam of good ideas and solutions (Brennan and Dooley 2005). 


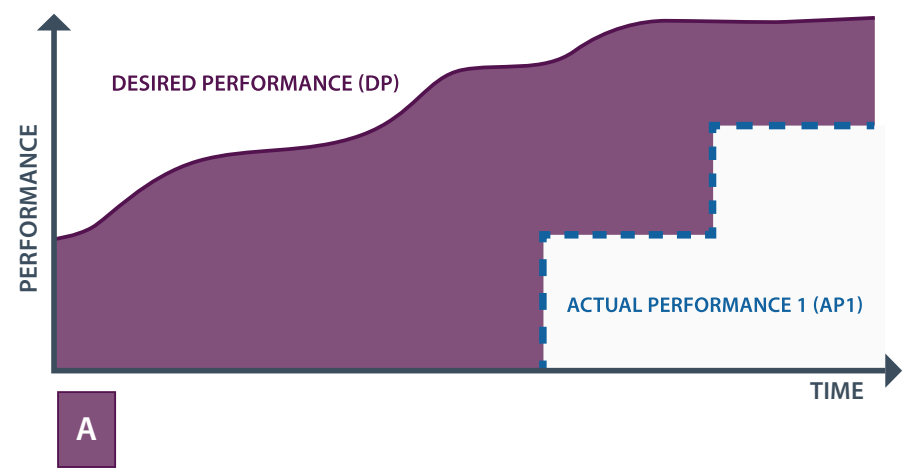

Fig. 4 Meeting increased performance demands through discrete upgrade increments

The idea behind a continual upgrade strategy is to initiate and implement relatively small but frequent change increments to minimise the gap between customers' desired performance and the actual system performance (Fig. 4).

Figure 4 shows two curves: desired performance (DP) and actual performance 1 (AP1). DP is the performance of an IPSS as desired by the owner or user of the IPSS. This performance increases over time in waves. Reasons are new technological developments or new demand and requirements of final customers. AP1 is the performance the current installed IPPS can provide. AP1 is improved by two stepwise increments. The decision to improve the actual performance, i.e., the decisions to upgrade the assets by investing depend on multiple factors; for example, ease of upgradability of the asset, the direct cost and benefits of upgrading, and the (more indirect) potential loss in customer and market share, if the IPSS is not upgraded. Figure 4 shows a large area A which represents the "area of loss" due to not upgrading frequently. In the figure, it is assumed that the two upgrading increments cannot improve the performance to the latest DP but that there is a significant gap.

With the UIW-approach, the IPSS can be upgraded more frequently as Fig. 5 shows. The objective of the UIW-framework is to minimize the area of loss, i.e., the area between the DP and actual performance by using continual, i.e., more frequent and smaller improvements. As Fig. 5 indicates, AP2 is much closer to DP as AP1. The previous "area of loss" A could be reduced to the area A'. In other words, the UW-approach aims to avoid the loss of area B.

\subsection{Integrative Flexibility}

Due to the continuously changing settings and the variety of networks firms will have to be involved in, it is not possible to develop a fixed solution capable of meeting all needs. Therefore, the solution must be flexible. It must be capable of adapting to various scenarios and it must be capable of evolving over time. 


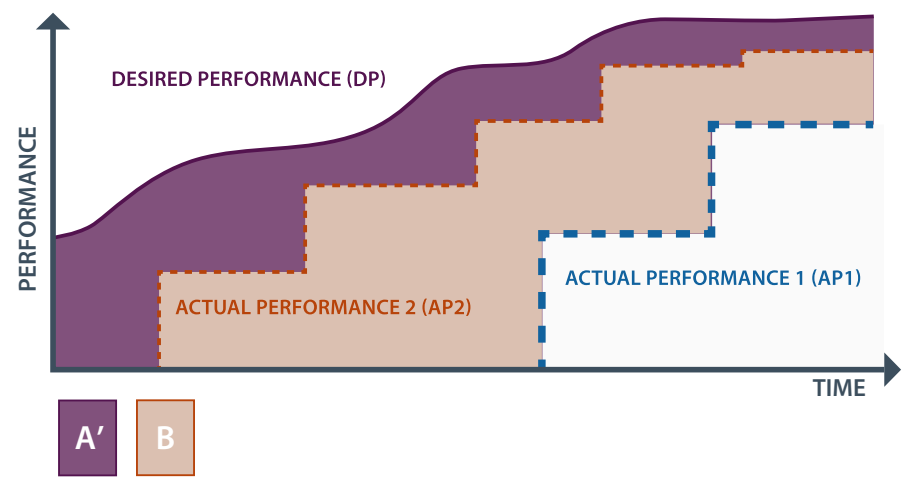

Fig. 5 Meeting increased performance demands through more frequent discrete upgrade increments

The UIW-approach is aiming to serve a wide range of industries and diverse upgrade needs. The approach is by design generic to provide sufficient flexibility to adapt to different use cases and scenarios in manufacturing industry at large. The tools and methods described in the approach are selected to serve a variety of user groups in each application case. This is necessary to enable actors across the value network to contribute effectively to the upgrade process bringing in knowledge and experience beyond what is available in traditional R\&D teams.

The UIW-approach is also designed to cover a broad range of functions, including business development and decision making, engineering data management and life cycle support. Thus, it supports an integration of functions both horizontally across the life-cycle and vertically "from shop-floor to top-floor".

\subsection{Collaborative Innovation}

The capacity to innovate determines a firm's capability to survive in the global competition and meet the challenges of changing markets. In search for competitive strength firms have developed new strategies involving external resources in product design and customer adaptation. This is based on the insight that important knowledge about the product, and especially of its use, resides outside of the corporate boundaries.

End-user collaboration is frequent in consumer products and services where users are asked to provide feedback on designs, or mobilised in collaborative ideation about future products or services. This goes beyond traditional requirements management processes based on an elicitation of user needs and specified sets of requirements. Hienerth et al. (2014) have studied the efficiency of user vs. producer innovation and found that even an uncoordinated group of users can be as or more efficient than the specialized producer innovators. Companies can also seek 
increased innovation capacity in collaboration with each other. However, collaborative innovation is more common in radical innovation than in continuous improvement (Chapman and Corso 2005).

The need for increased collaboration across the value network is also a direct consequence of the shift towards a service-dominant business logic where value is determined by the consumer and produced as a collaborative effort of the value network (Vargo et al. 2008). Opening parts of a firm's innovation process to external actors is a strategic decision with important implications on, for instance, operational cost, value and knowledge creation, intellectual rights management. The decision should therefore be guided by careful analysis of technical and financial viability of different types and levels of collaboration. However, open, collaborative innovation models are fundamentally different from traditional organisation centred ones especially with respect to where in the network knowledge is accumulated and innovation created (Lakhani et al. 2012). This requires a new mode of thinking where shared knowledge is regarded as a competitive advantage of the collaboration network instead of a strategic in-house asset.

\subsection{Sustainability}

Increasing awareness of human activities on nature as a global habitat, as well as the depletion of natural resources has put increasing pressures on manufacturers to ensure environmental sustainability of their products and services. The requirements are enforced by public opinion driving market forces, and by international treaties and legislation. As a result, sustainability turns from a cost driver to an opportunity for companies leading the development.

The trend of sustainable product development is shifting from reduce, reuse and recycle to include also recover, redesign and remanufacture, and leading to the implementation of multiple generation life-cycle products (Go et al. 2015). This defines a transition from linear life-cycle process to a process based on a circular economy (Ellen MacArthur Foundation 2013). More details can be found in Pajula et al. in Chapter "Managing the Life Cycle to Reduce Environmental Impacts" of this book.

Environmental sustainability is a driver for new products and markets based on new environmental friendly technologies. On the other hand, sustainability goals also motivate life extension of existing systems (EFFRA 2013). Thus, sustainability improvement becomes an important upgrade objective.

Extending operational life cycles contribute to ecological values by postponing energy- and material-intensive system renewals, provided that the system can be operated in an environmentally sustainable manner. 


\subsection{Model-Based Engineering and Data Management}

The growing complexity of technical systems calls for high levels of specialisation. Complex, interlinked systems of systems (SoS), therefore, have to rely on a close collaboration between a large number of actors across the value chain. Managing complex engineering processes involving multiple actors requires a systematic approach and efficient data management. The quantity of system documentation generated over the life-cycle of complex engineering artefacts quickly becomes unmanageable for human operators and may lead to design errors, expensive rework and added risk. Model-based systems engineering (MBSE) approaches aim to reduce and eventually replace document-centred system data management. Transitioning from human-readable text based information to model-based representations makes it possible to automate design tasks and ensure data consistency. Human readable (e.g. graphical) system modelling notations may also help communication across diverse design disciplines and between actors with different native languages (Vitech Corporation 2011). System data must also be managed in a reliable way while ensuring security and confidentiality of sensitive data from various collaborating parties. Chapter "Extending the System Model" of this book deals in more detail with the question of system modelling in complex design environments.

\section{The UIW-Approach Supports Continuous Upgrades}

To deal with the challenge of meeting the changing needs of an increasing group of customers requesting personalized solutions and life-cycle support, a generic approach for managing system upgrades of IPSS has been developed. The purpose of the approach is to facilitate a life-long upgrade process of IPSS aiming to extend the profitable service-life by enabling continuous adaptation to changing requirements. The approach combines theory knowledge, best practice and supporting tools and technologies.

The underlying idea is that successful IPSS upgrades require a comprehensive approach where the design of individual upgrade steps is not only based on single customer needs and feasibility analysis, but on a holistic understanding of the system in relation to the dynamic environment. This requires capturing extensive system knowledge form a wide spectrum of actors, including customers, end users, designers, operators, and marketing staff. The approach combines this comprehensive system knowledge with theory knowledge of experts with access to relevant tools, methods, and technologies for system analysis, decision making and process support.

The UIW-approach supports a collaborative innovation and design process in which each upgrade step is based on close interaction and knowledge sharing between involved actors. Through this collaboration, knowledge about the systems 
performance as well as changes to the operating environment, market changes, and other external factors are systematically collected and shared. At the core of the collective knowledge base is a generic representation of an upgrade innovation process (Fig. 6). The process supports collaborative and concurrent upgrade innovation. Collaborative innovation involves engaging actors, such as workers, designers, end uses, managers and sales staff, in a collaborative effort to solve identified problems. In the first phase problem solving involves identifying problems and their root causes, and finding possible solutions through creative ideation. The purpose of the ideas is to take the system from its current state ("as is") to a desirable future state ("to be").

The collaborative ideation produces ideas and suggested solutions to transform the system from the current state to a desirable future state. The proposed solutions are tested in the analytic cycle using simulation and analysis tools. The results of the simulations may show that the ideas are insufficient to transform the system to the target state. The discrepancy between the target future state and the simulated future state provide input to further ideation and refinement of proposed solutions. The simulations may also show that the future target state is unrealistic, given the existing system parameters, in which case a re-evaluation of possible target stages is necessary.

The process described in Fig. 6 applies two separate modes of thinking: the ideation cycle represent the fast, intuitive and associative "System 1" thinking and the analytic cycle represents the slow and analytic "System 2" (Kahneman 2011). Separating the two modes of thinking aims to enable, on the one hand, a creative ideation process free from the restrictions of premature analysis and rejection, and on the other hand an analytic cycle with an abundant flow of input in the form of new ideas. The ideation and analytic cycles, although separated, run in parallel forming a concurrent engineering environment where solutions and ideas are thoroughly tested before proceeding to production and implementation. The integration of key actors in the process ensures that upgrade solutions are not only tested for technical and economic feasibility, but also evaluated against the needs and system knowledge of end users.

The UIW-approach comprises three main elements: the UIW-framework; the UIW-web platform, and; the UIW-virtual community. These are introduced next.

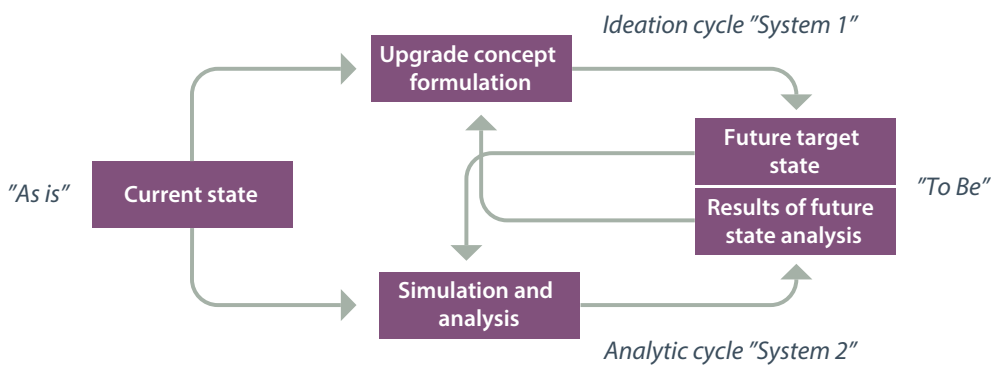

Fig. 6 Collaborative upgrade innovation process 


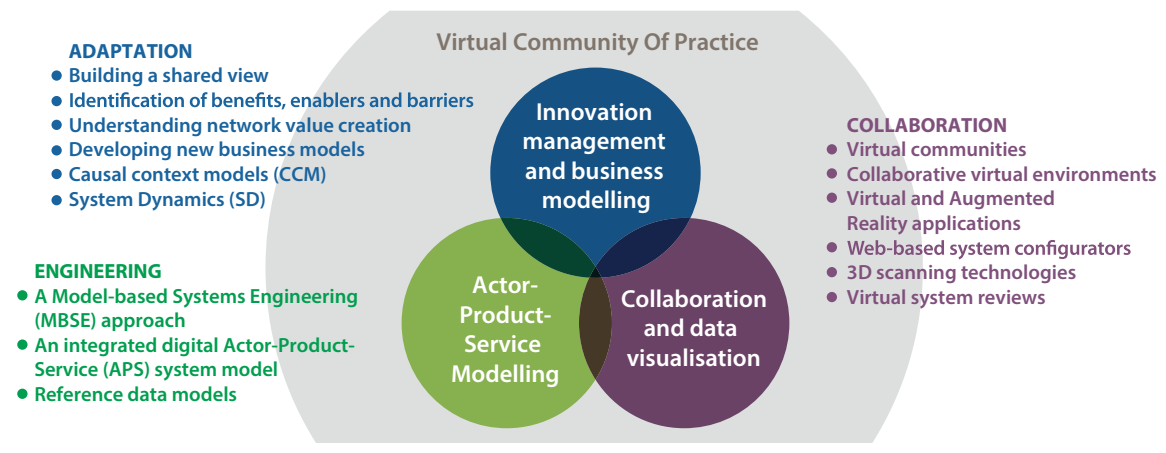

Fig. 7 The UIW-framework

\subsection{The UIW-Framework}

The purpose of the UIW-framework is to support a comprehensive approach to a continuous innovation process for a life-long adaptation of industrial product-service systems by outlining a generic solution to be further specified and implemented in actual use cases. The framework covers three main areas: adaptation, collaboration and engineering. Reflecting the analysis of the imaginary industrial company in Chapter "The Challenge", the UIW-framework describes three complementary sets of modelling solutions targeting the application areas. A number of tools and methods are suggested in each of the model categories. Figure 7 shows a schematic overview of the UIW-framework indicating tools and methods associated with the different sections.

Established actor networks select the best tools on a case-by-case basis to set up a dedicated upgrade innovation platform for a specific IPSS. The tools are then adapted, modified or extended to meet the specific needs in each case. Both the use and the adaptation of the tools may require special skills which may be offered by members of the Community of Practice. New, modified or extended tools are returned to expand the platform and to serve future needs. The following sections describe the model categories in more detail.

\subsubsection{Innovation Management and Business Modelling}

The purpose of innovation management and business modelling is to support the continual adaptation of the system in order to find optimal upgrade solutions to meet changing needs and exploit new opportunities. The key element is a shared understanding of the business dynamics of the upgrade case. This includes identifying influential actors, their motives and capabilities, and understanding how value is created and shared within the network. Rich pictures, Causal Context Models (CCM) and System Dynamics (SD) simulation can be used as tools 
(see Groesser, Chapter “Complexity Management and System Dynamics Thinking” in this book). The model emphasizes a shared effort between the actors to learn about system dependencies and the effect of change. A comprehensive, shared view on actor roles and interests, as well as an understanding of the effects of potential future development, help establishing new competitive business models. The adaptation model can later be used to identify and simulate the effects changes in the business environment, thus supporting decision making in later stages of the systems life-cycle.

The UIW-web-platform includes resources for constructing a bespoke adaptation model, in the form of a selection of model exemplars. These exemplars can be extended and configured to meet specific requirements of actual upgrade cases. The platform also provides resources in the form of expert support on setting up and working with the models.

\subsubsection{Collaboration and Data Visualisation}

One of the key elements of the UIW-approach is a close and continuous interaction between involved actors. This is supported by digital tools for collaboration and data visualisation. Collaboration between diverse groups of actors with different interest, motives and professional background differs substantially from collaboration between individuals of in-house R\&D teams or other established networks of a more stable nature. In addition to social or professional distribution actors may also be spatially distributed, separated by distance, time zones or language barriers. To enable efficient communication and active collaboration between network actors the framework suggests various tools for shared virtual system representations based on Virtual Reality (VR) and Augmented Reality(AR) and tools for retrieving the and presenting necessary $3 \mathrm{D}$ information. Current internet-based communication solutions offer multiple options for establishing collaboration networks capable of operating effectively regardless of physical distance. VR and AR technologies can be used to provide users with a realistic and interactive virtual representation of target system or the operating environment, making it possible to try out and comment on suggested upgrade solutions. The use of visualisation techniques based on virtual and augmented reality to create shared views is presented in Chapter "Virtual Reality and 3D Imaging to Support Collaborative Decision Making for Adaptation of Long-Life Assets" and was implemented in several pilot cases presented in Part III of this book.

In addition to technological solutions the UIW-framework also contains guidelines for establishing and maintaining active actor communities or virtual Communities of Practice (CoP). CoPs are seen as an efficient way to foster a continuous dialog between actors to share knowledge and support the generation of new ideas. The collaboration model should enable an ongoing exchange of information through the system life, also between individual upgrade increments. Principles for establishing successful CoPs are treated in Chapter "Fostering a Community of Practice for Industrial Processes". 


\subsubsection{Actor-Product-Service Modelling}

Designing complex product-service systems require the combined efforts of large engineering teams and a diversity of different domain experts. When the system undergoes repeated upgrades during their life-cycle a well-managed engineering process is necessary. The UIW-framework strongly supports the use of shared digital system models to capture all system life-cycle data to enable efficient collaborative engineering based on MBSE principles. An extension of the product-centric data model is proposed. The extended actor-product-service (APS) system model includes data relating to actors and product-based service. Reference data models have been developed, but actual implementations must be designed separately in each case to account for specific needs and requirements of individual actors. Especially technical restrictions or incompatibility issues between different data systems used by various actors may limit the implementation of an optimal shared APS system model. Transitioning from a document-based design process to a MBSE approach promises to facilitate automation of design information by introducing a more generic, symbolic system representation, overcoming the limitations of written text is described in Chapter "Extending the System Model".

\section{The UIW-Web Platform}

The purpose of the UIW-web platform is to work as a public front-end combining the outcomes of the project and making them available to external audiences. The platform also provides access to expert knowledge and services related to the implementation of the tools and models in future upgrade cases and hosts a virtual community of practice within which members can share their experience and generate new knowledge in a continuous collaboration process.

UIW-web platform acts as a broker of information and services relating to the upgrading of industrial product-service systems. The platform website is available at http://use-it-wisely.eu.

\section{UIW-Virtual Community}

The UIW-virtual community brings together suppliers, customers, engineering experts and researchers focusing on upgrades of high-investment product-services. The community combines theory and practice knowledge across various fields of industry, and presents tools and methods applied in documented reference cases. The purpose of the virtual community is to ensure continuous development of the UIW-framework and to contribute to the accumulation of shared knowledge and resources. The combined resources generated through the sustained activities of the 
multi-domain collaborative community of practice are collected in a pool of collective knowledge, tools and methods accessible through the UIW-web platform. The community also provides access to information or expert services relating to the application of the various methods.

\section{Reference Cases}

The UIW-framework is an abstract building on the main idea of involving actors in a collaborative effort to sustain and create IPSS through upgrading. Practical implementation of the framework is supported through a community platform that provides access to knowledge and tools as well as expert advice to assist companies set up their own collaboration networks and toolsets to specific needs. The community platform is maintained at http://use-it-wisely.eu. The localised implementations of the framework may target a single product-service development case, a specific business area or build on the collaboration of a network with a shared interest looking for new opportunities. The objective may be technical improvement, taking advantage of new technology opportunities of business model innovation. Thus, all implementation instances will have their own characteristics with different adaptation systems, APS system models and virtual collaboration spaces. The use of the framework in dedicated update innovation projects improves existing tools and models, and generates new knowledge. Voluntary sharing this generated knowledge through the community platform contributes to the common knowledge base and promotes cross disciplinary learning shared across industry domains. Part III of this book presents implementation of the UIW-framework in six industry clusters.

\section{Conclusions}

Global competition in manufacturing industry and industrial services increase as emerging economies enter the market, and communication and logistics channels develop. Customers take advantage of the new opportunities and require solutions adapted to specific needs at competitive costs. Environmental sustainability becomes a high priority driven by legislation and social pressures. Companies need to find new ways to maintain their competitive advantage in the changing business landscape.

One way of approaching the challenges is to shift focus from tangible products to customer benefit. Rather than just offering add-on services there is a shift towards service-dominant business models where value is provided primarily as services or resources. This shift of business logic has important implications on how firms collaborate with the customer and other actors. The creation and utilisation of knowledge outside of traditional corporate boundaries becomes a prime target. 
The volatile market with fast moving market entrants and a continuous stream of new technologies poses specific challenges to well established industries supplying high-investment products with high long expected life-cycles. To meet changing requirements in different phases of the operational life, these systems need to be continually upgraded. Efficient maintenance and upgrade services may also enable an extended life-cycle, which brings savings to customers and contribute to environmental sustainability objectives.

In the UIW-project, co-funded by the European Commission and twenty companies, universities and research organisations, a generic approach was developed for enabling effective upgrade innovation and customer adaptation. The UIW-approach is based on close actor collaboration, a shared, holistic system view and effective information management to support life-cycle sustainability based on frequent, demand-led upgrade increments. Based on this approach a conceptual framework was created to help companies develop their upgrade innovation processes. The UIW-framework builds on three corner stones: an adaptation mechanism, consisting of tools and methods for a holistic view of influence factors and causal dependencies to support decision making and creation of upgrade strategies; an actor-product-service system model, integrating product and actor data with a model-based systems engineering approach for a comprehensive and up-to-date digital system representation throughout the life-cycle; and a collaborative virtual environment, to support upgrade innovation by connecting actors in a collaborative effort independent of location.

The UIW-framework is supported by a collection of selected tools and methods, best practice information and selected reference cases made available through a community web site. The site is maintained by a virtual community bringing together practitioners and researchers in a continuing effort to further develop tools and methods and build on the collective knowledge of the community. The framework does not describe a strict process or prescribe specific tools to be used. Instead, it proposes a number of viewpoints and suggests tools and methods to support analysis, decision making and collaboration based on the previous research knowledge and practical experience from the pilot cases. This makes the framework agile to adjust to upgrade cases beyond those treated in the current project and to other sectors of industry. The framework itself is intended to be extended and upgraded based on resources and experience gained from future case studies.

The approach and related tools were tested in six clusters representing a broad variety of industries. Some examples of the tools and their use in the process are presented in Part II of this book. Industrial implementation cases are presented in Part III. 


\section{References}

Anderson, V., \& Johnson, L. (1997). Systems thinking basics: From concepts to causal loops. Waltham, Massachusetts: Pegasus Communications Inc.

Bessant, J., \& Caffyn, S. (1997). High-involvement innovation through continuous improvement. International Journal of Technology Management, 14(1), 7.

Brennan, A., \& Dooley, L. (2005). Networked creativity: A structured management framework for stimulating innovation. Technovation, 25, 1388-1399.

Burt, R. S. (2011). Structural holes and good ideas. The American Journal of Sociology, 110(2), 349-399.

Chapman, R. L., \& Corso, M. (2005). From continuous improvement to collaborative innovation: The next challenge in supply chain management. Production Planning \& Control, 16(4), 339-344.

EFFRA. (2013). Factories of the future: Multi-annual roadmap for the contractual PPP under Horizon 2020. Publications Office of the European Union.

Ellen MacArthur Foundation. (2013). Towards the circular economy (Vol. 1). Available at: http:// www.thecirculareconomy.org

Engel, A., \& Browning, T. R. (2006). Designing systems for adaptability by means of architecture options. INCOSE International Symposium, 16(1), 237-258.

Fink, A., Siebe, A., \& Kuhle, J.-P. (2004). How scenarios support strategic early warning processes. Foresight, 6(3), 173-185.

Fox, S., \& Groesser, S. N. (2016). Reframing the relevance of research to practice. European Management Journal, 34(5), 457-465.

Go, T. F., Wahab, D. A., \& Hishamuddin, H. (2015). Multiple generation life-cycles for product sustainability: The way forward. Journal of Cleaner Production, 95, 16-29.

Gunasekaran, A., Lai, K. H., \& Edwin Cheng, T. C. (2008). Responsive supply chain: A competitive strategy in a networked economy. Omega, 36(4), 549-564.

Hienerth, C., von Hippel, E., \& Berg Jensen, M. (2014). User community vs. producer innovation development efficiency: A first empirical study. Research Policy, 43(1), 190-201.

Imai, M. (1986). Kaizen: The key to Japan's competitive success. New York: Random House.

Kahneman, D. (2011). Thinking, fast and slow (1st ed.) New York: Farrar, Straus and Giroux.

Lakhani, K. R., Lifshitz-Assaf, H., \& Tushman, M. (2012). Open innovation and organizational boundaries: The impact of task decomposition and knowledge distribution on the locus of innovation. SSRN Electronic Journal.

Müller, A. W., \& Müller-Stewens, G. (2009). Strategic foresight. Stuttgart: Schäffer-Poeschel.

OECD. (2015). The innovation imperative: Contributing to productivity, growth and well-being. Paris: OECD Publishing.

Parker, D., et al. (2015). Remanufacturing market study. European Remanufacturing Network.

Rajkumar, R., (Raj) et al. (2010). Cyber-physical systems. In Proceedings of the 47th Design Automation Conference on-DAC'10, p. 731.

Schulz, A. P., \& Fricke, E. (1999). Incorporating flexibility, agility, robustness, and adaptability within the design of integrated systems - Key to success? In Gateway to the New Millennium. 18th Digital Avionics Systems Conference. Proceedings (Cat. No. 99CH37033) (Vol. 1/17, pp. 1-8).

Schulz, A. P., Fricke, E., \& Igenbergs, E. (2000). Enabling changes in systems throughout the entire life-cycle-Key to Success? In Proceedings of the 10th Annual INCOSE Conference, July 2000, Minneapolis, USA. 
UNIDO. (2013). Emerging trends in global manufacturing industries. Report of the United Nations Industrial Development Organization. Vienna. Retrieved from http://www.unido.org/ fileadmin/user_media/Services/PSD/Emerging_Trends_UNIDO_2013.PDF

Vargo, S. L., Maglio, P. P., \& Akaka, M. A. (2008). On value and value co-creation: A service systems and service logic perspective. European Management Journal, 26(3), 145-152.

Vitech Corporation. (2011). A primer for model-based systems engineering.

Open Access This chapter is licensed under the terms of the Creative Commons Attribution-NonCommercial 4.0 International License (http://creativecommons.org/licenses/by-nc/ 4.0/), which permits any noncommercial use, sharing, adaptation, distribution and reproduction in any medium or format, as long as you give appropriate credit to the original author(s) and the source, provide a link to the Creative Commons license and indicate if changes were made.

The images or other third party material in this chapter are included in the chapter's Creative Commons license, unless indicated otherwise in a credit line to the material. If material is not included in the chapter's Creative Commons license and your intended use is not permitted by statutory regulation or exceeds the permitted use, you will need to obtain permission directly from the copyright holder.

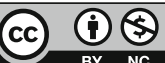

